\title{
ANALYSIS AND DESIGN INFORMATION SYSTEM LOGISTICS DELIVERY SERVICE IN PT REPEX WAHANA
}

\author{
Stephanie Surja ${ }^{1}$; Lius Steven Sanjaya ${ }^{2}$ \\ 1,2Information Systems Department, School of Information Systems, BINUS University \\ Jl. KH. Syahdan No. 9, Palmerah, Jakarta Barat 11480 \\ ${ }^{1}$ surjastephanie@gmail.com; ${ }^{2}$ liusstevens@gmail.com
}

\begin{abstract}
Analysis and Design of Logistic Delivery System in PT Repex Wahana aims to analyze company's need in existing business process of logistic delivery service. This will then be used in the development of an integrated system that can address the problems in the running process of sending and tracking the whereabouts or status of the delivered goods which are the core business processes in the enterprise. The result then will be used as basis in the development of integrated information system in pursuit of corporate solution for process business automation, delivery process, inventory, and logistic delivery tracking, which is the core of the company business process, and it will be documented using Unified Modeling Language. The information system is meant to simplify the delivery and tracking process in the company, besides will minimize lost and error of data which is often happened because of the manual and unorganized transaction data processing.
\end{abstract}

Keywords: Analysis and Design, Information System, Logistic

\begin{abstract}
ABSTRAK
Analisa dan perancangan sistem jasa pengiriman logistic pada PT Repex Wahana bertujuan untuk menganalisa kebutuhan perusahaan dalam proses bisnis jasa pengiriman logistik yang terkait dengan proses bisnis yang sedang berjalan. Hal ini akan kemudian digunakan dalam pengembangan sebuah sistem yang terintegrasi yang dapat menjawab permasalahan perusahaan di dalam menjalankan proses pengiriman serta melacak keberadaan atau status barang yang dikirim yang merupakan inti di dalam proses bisnis perusahaan. Hasil analisa lalu akan digunakan sebagai dasar pengembangan sistem informasi terintegrasi untuk mencapai tujuan perusahaan terhadap otomatisasi proses bisnis pengiriman, inventori dan pelacakan pengiriman logistic, yang merupakan inti dari proses bisnis perusahaan dan akan didokumentasikan dengan menggunakan Unified Modeling Language. Dengan adanya sistem informasi ini diharapkan mampu mempermudah proses pengiriman serta pelacakan barang pengiriman di dalam perusahaan, di samping itu juga dapat meminimalisir kehilangan atau kesalahan data yang sering terjadi karena penyimpanan data transaksi yang dilakukan secara manual dan tidak terorganisir.
\end{abstract}

Kata kunci: Analisa dan perancangan, sistem informasi, logistic 


\section{PENDAHULUAN}

Di era teknologi informasi ini dalam menghadapi persaingan hampir seluruh perusahaan berlomba-lomba untuk melakukan upgrade proses bisnis yang sebelumnya masih manual menjadi sebuah proses bisnis terintegrasi dengan mengimplementasikan sistem informasi di dalam perusahaan. Kebanyakan perusahaan yang lebih memilih untuk tidak meningkatkan sistem lama yang sudah ada dalam perusahaan mereka akan mengalami kekalahan dari para pesaing yang bergerak dalam bisnis serupa.

Sebuah sistem informasi yang dapat mengintegrasikan seluruh proses bisnis berjalan di sebuah perusahaan merupakan salah satu faktor penting agar perusahaan tersebut untuk dapat berkembang dan tidak tertinggal oleh para pesaing (O’Brien, 2005). Sistem informasi yang terintegrasi bahkan dapat memberikan keuntungan kompetitif bagi perusahaan dan menjadi leader dari perusahaan yang bergerak dalam proses bisnis sejenis. Dengan adanya sistem yang dapat memproses seluruh kegiatan operational dan menyimpan data transaksi yang ada maka perusahaan dapat dengan mudah mengelola data yang menjadi kunci dalam strategi bisnis, sehingga hal ini dapat membantu perusahaan untuk dapat bersaing dengan lebih baik.

PT Repex Wahana merupakan sebuah perusahaan yang bergerak di bidang jasa khususnya logistik baik domestik maupun internasional. Repex Group yang sebelumnya bernama PT Republic Express ini didirikan pada tanggal 13 April 1982 dengan memiliki moto Citilink yang pada umumnya menangani pengiriman Asia Tenggara. Saat ini perusahaan yang memiliki lebih dari 200 mobil van dan truk, 80 kendaraan bermotor, dan 2 pesawat terbang, serta gudang yang kurang lebih sebesar 100 $\mathrm{m}^{2}$ dalam mendukung kegiatan bisnisnya, berlokasikan di Jl Ciputat Raya No.99, Pondok Pinang, Jakarta Selatan. PT Repex Wahana yang sudah mengantongi Lisensi dari Federal Express (FedEx) sangat ingin tumbuh dan berinovasi demi bertahan dan memenangkan pasar yang terus berkembang pesat saat ini. Perusahaan mencari peluang untuk menjawab tantangan-tantangan dalam usaha perseroan terbatas ini.

Dilihat dari cara PT Repex Wahana melakukan bisnis, letak permasalahan perusahaan ini terletak pada proses bisnis itu sendiri yang masih bersifat tradisional dan masih bergantung pada catatan fisik dan masih menggunakan kertas sebagai media untuk menyimpan data-data penting yang diperlukan (Alianto, 2011). Oleh karena itu, penelitian ini berusaha memberikan solusi dengan cara menganalisa proses bisnis yang berjalan dalam perusahaan tersebut dan membuat usulan rancangan sistem informasi yang dapat meningkatkan efektivitas, efisiensi dan produktivitas kerja perusahaan (Whitten, 2007).

Menurut Satzinger (2011) sistem informasi adalah seperangkat komponen komputer yang saling terkait yang mengumpulkan, memproses, menyimpan (biasanya dalam database), dan menyediakan sebagai output informasi yang dibutuhkan untuk menyelesaikan tugas-tugas bisnis. Menurut Nickels (2010) dalam logistik adalah perencanaan, pelaksanaan dan pengendalian aliran fisik material, barang jadi dan informasi terkait dari titik asal ke titik konsumsi.

\section{METODE}

Penelitian ini dimulai dari pembelajaran dan analisa kasus perusahaan terlebih yang kemudian disusul dengan tinjauan pustaka dan analisa terhadap proses bisnis jasa pengiriman logistik demi mendapatkan kebutuhan-kebutuhan perusahaan yang menjadi syarat keperluan di dalam sistem informasi yang akan dibangun pada PT Repex Wahana. Dokumentasi atas hasil analisa pada PT Repex Wahana akan dilakukan dengan menggunakan Unified Modeling Language yang didasarkan pada standar Satzinger (2011). 


\section{HASIL DAN PEMBAHASAN}

\section{Proses Bisnis Berjalan}

Pelanggan yang ingin mengirimkan barang dapat langsung mendatangi cabang RPX terdekat dan melakukan pendataan untuk pengiriman barang berupa pengisian formulir online yang akan dibantu langsung oleh front-end staff RPX untuk kemudian disimpan langsung dalam sistem. Di dalam formulir tersebut, pelanggan perlu memberikan informasi berupa nama pengirim, nomor telepon pengirim, nama penerima, alamat penerima dan nomor telepon penerima.

Setelah pengisian formulir selesai maka pelanggan akan dikenakan biaya sesuai tipe servis dengan rate dan dimensi barang maupun berat barang yang akan dikirimkan. Setiap pembayaran yang dilakukan akan kemudian disimpan dalam sistem dan pelanggan akan diberi invoice sesuai dengan transaksi yang dilakukan. Staff RPX kemudian akan memberikan barang tersebut ke courier, tapi apabila pengiriman bertujuan internasional, maka barang akan diberikan ke FedEx

Apabila courier atau FedEx telah menerima barang, mereka akan mengubah status barang menjadi "proses pengiriman" di sistem. Setelah itu, courier atau FedEx akan mengirim barang ke alamat tujuan. Apabila penerima telah menerima barang, penerima akan diminta untuk menandatangani surat bukti penerimaan barang.

Courier atau FedEx kemudian akan memasukkan data penerimaan barang yang terdiri dari ID pengiriman, nama penerima, serta tanggal penerimaan barang oleh penerima ke system. RPX akan mengecek data penerimaan barang. Apabila data penerimaan barang sudah ada, maka RPX akan merubah status pengiriman menjadi delivered di sistem. Customer dapat mengecek delivery status melalui website yang telah disediakan oleh pihak RPX.

\section{Permasalahan yang Dihadapi}

Customer tidak dapat mengecek status mengenai barang yang dikirim. Seluruh proses bisnis di RPX masih dilakukan secara manual sehingga sering terjadi human error yang mengakibatkan penginputan berulang kali untuk data yang sama. Membutuhkan waktu yang cukup lama dalam pencarian informasi yang dibutuhkan untuk membuat dokumen-dokumen yang diperlukan karena dilakukan secara manual dikarenakan pencatatannya yang masih manual.

\section{Usulan Pemecahan Masalah}

Pemecahan masalah untuk PT Repex Wahana adalah membuat suatu sistem informasi untuk bagian pendataan dan pengiriman yang saling terintegrasi dengan baik untuk seluruh proses operasional yang ada. Sistem informasi yang terintegrasi ini untuk memudahkan perusahaan dalam mendata seluruh pengiriman yang mereka lakukan. Perusahaan juga dimudahkan dalam mencari informasi yang diperlukan untuk strategi bisnis mereka sehingga meningkatkan pengiriman menggunakan sistem informasi tersebut 


\section{Activity Diagram: Usulan Proses Bisnis}

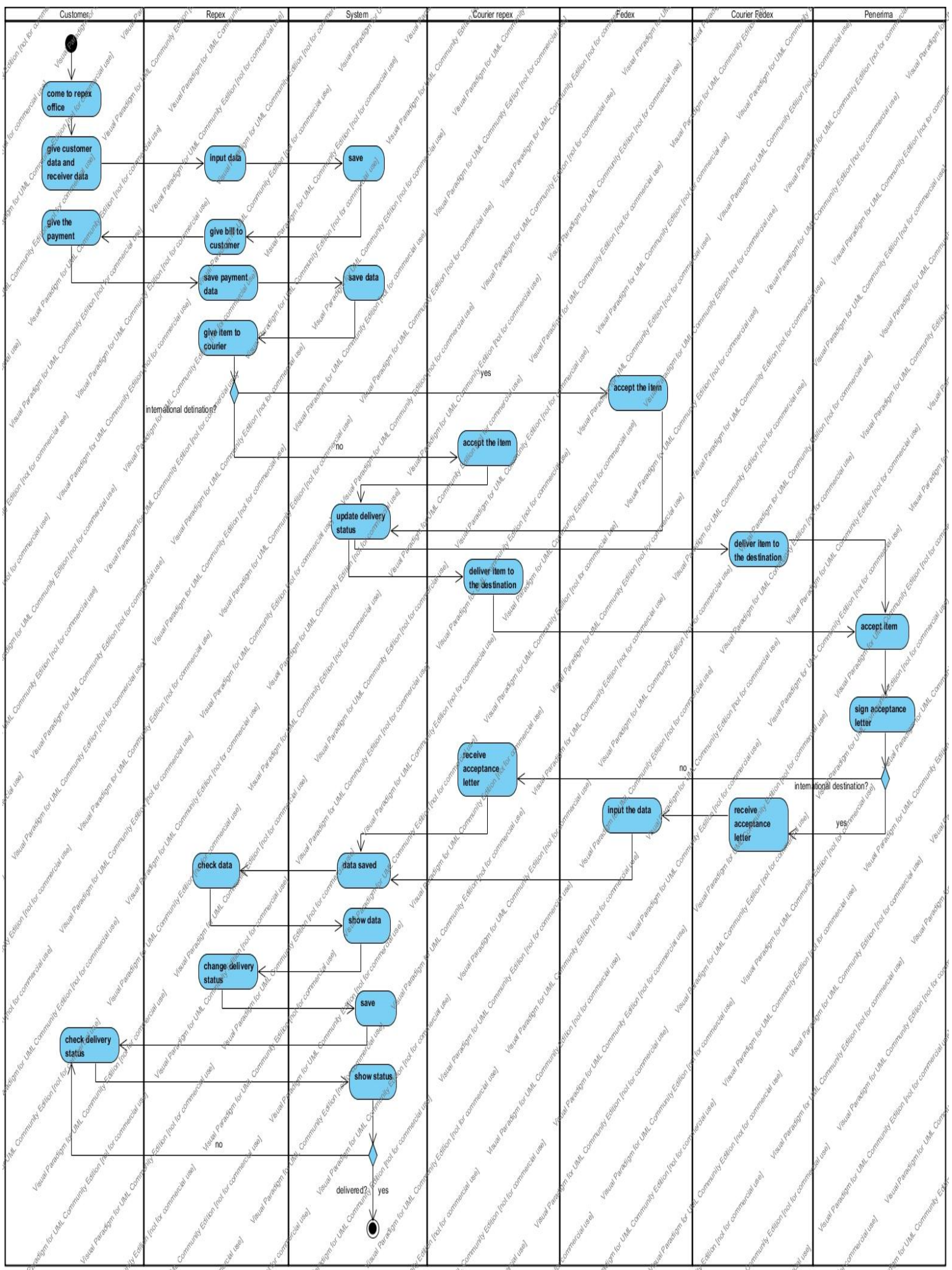

Gambar 1 Activity Diagram untuk Tata Laksana Sistem yang Diusulkan 


\section{Domain Class Diagram}

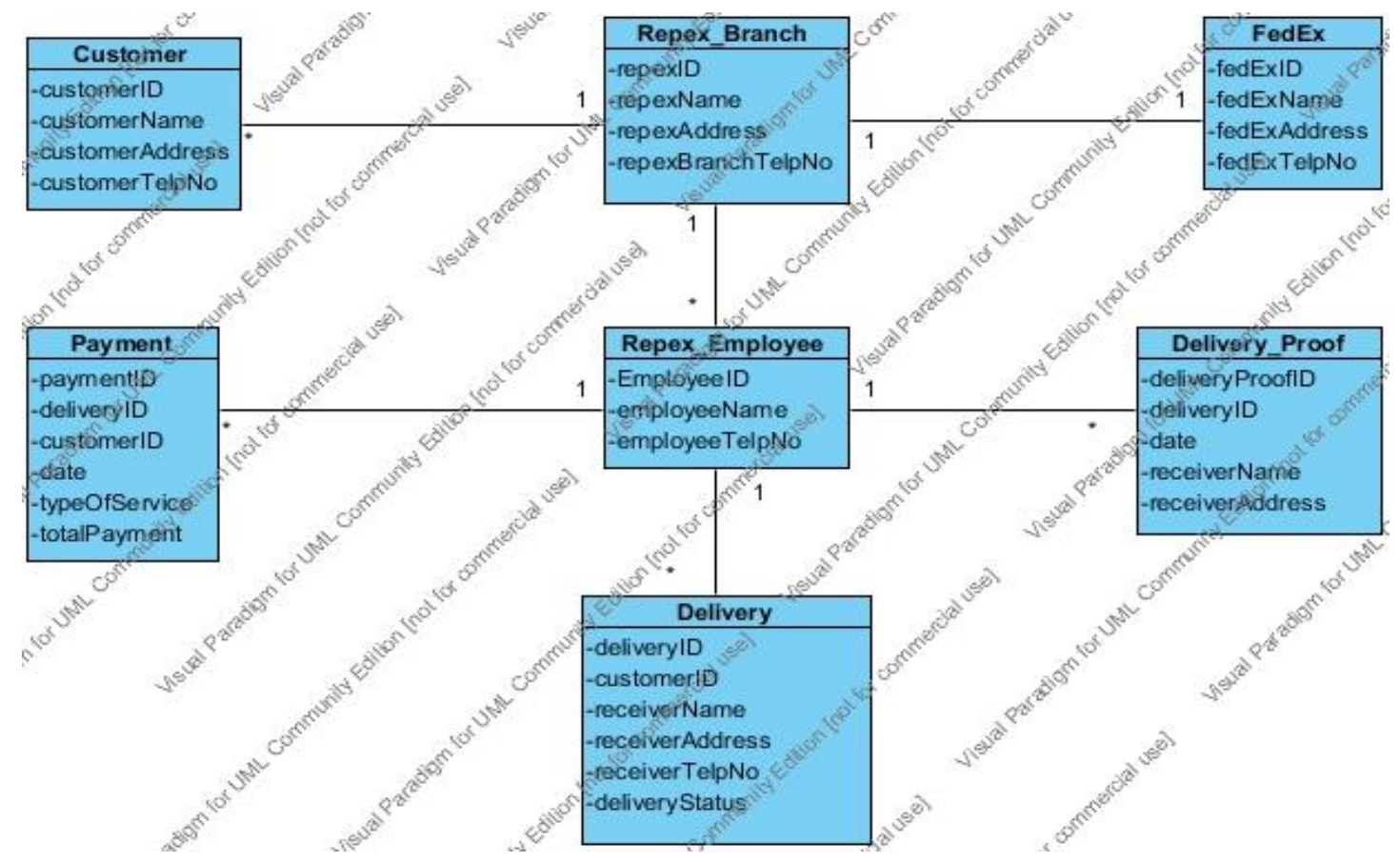

Gambar 2 Domain Class Diagram

\section{Use Case Diagram}

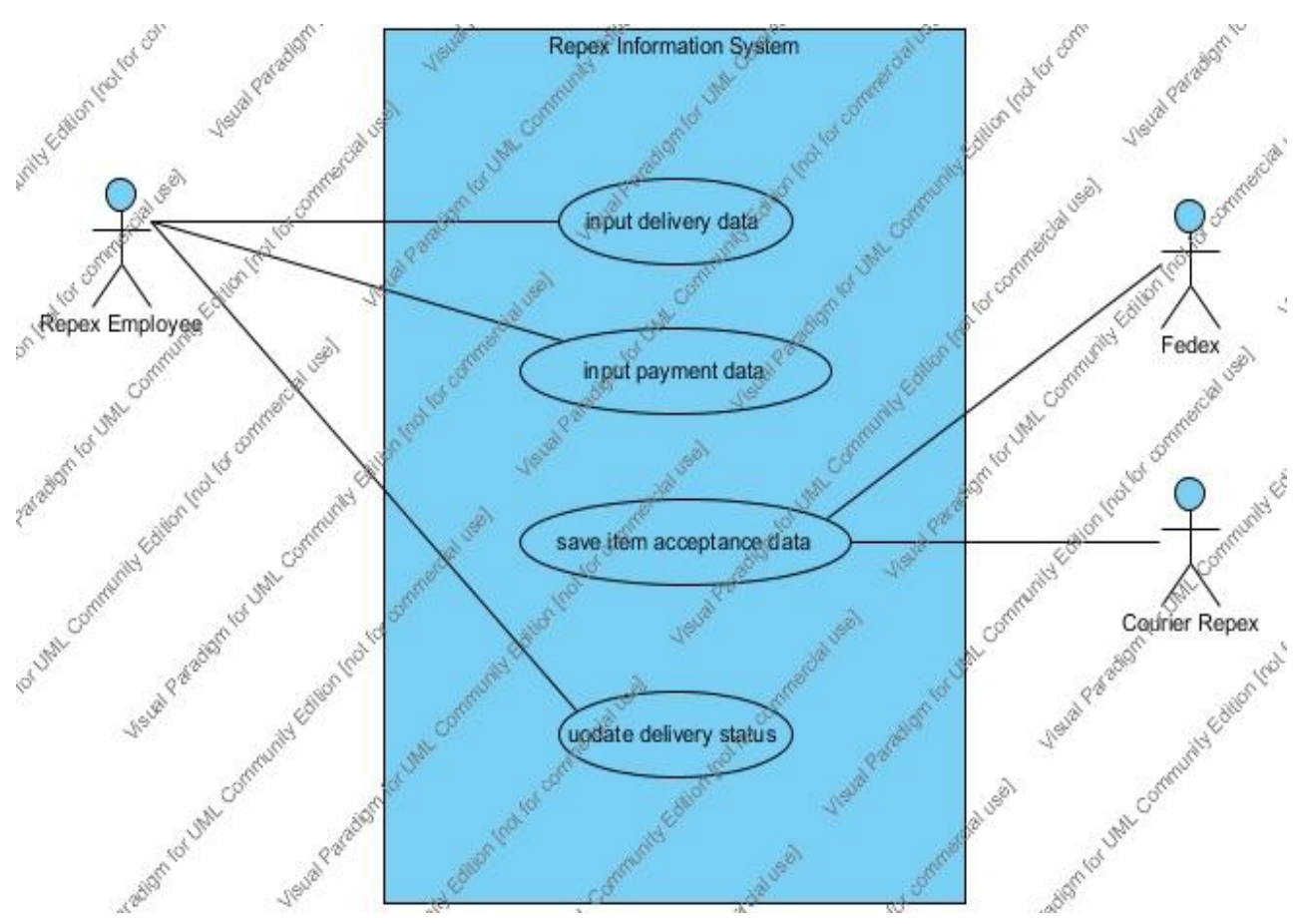

Gambar 3 Use Case Diagram 


\section{System Sequence Diagram (SSD)}

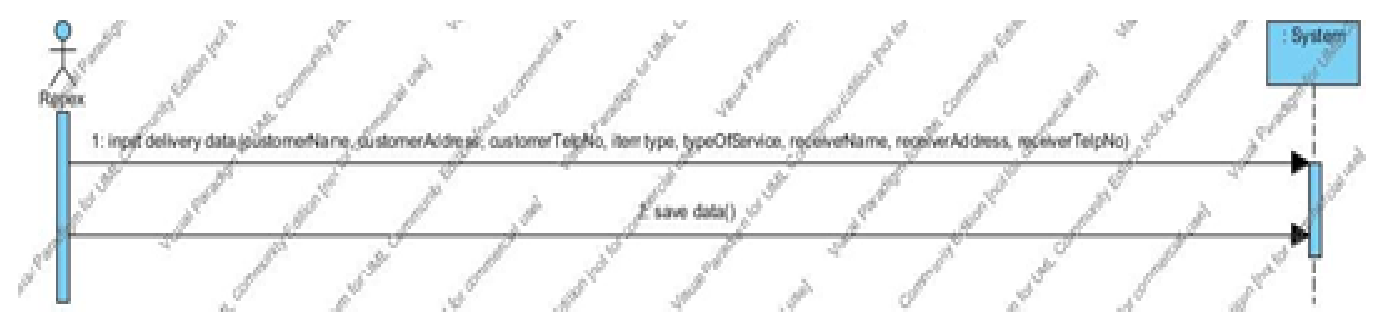

Gambar 4 SSD: Input Delivery Data

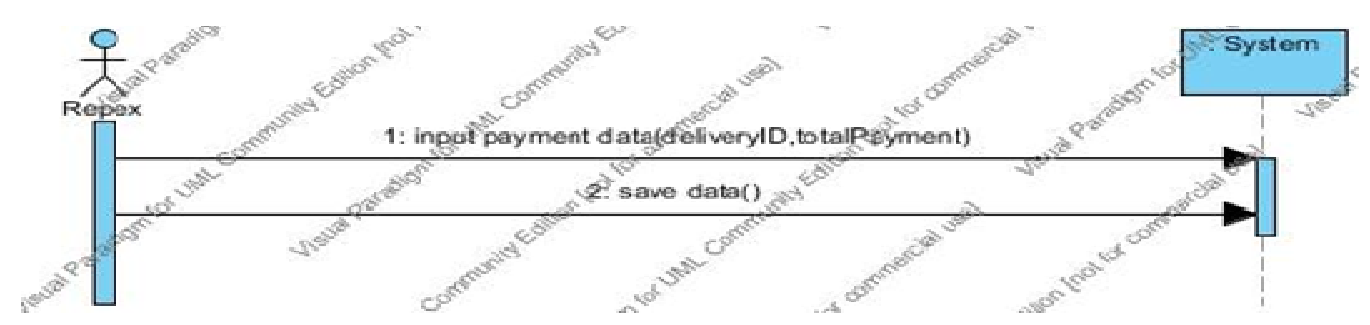

Gambar 5 SSD: Input Payment Data

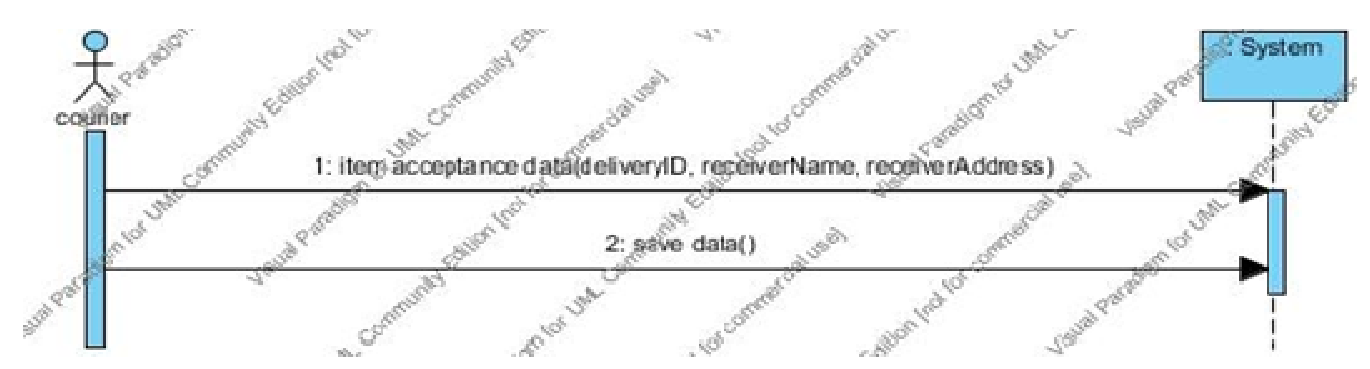

Gambar 6 SSD: Input Item Acceptance Data

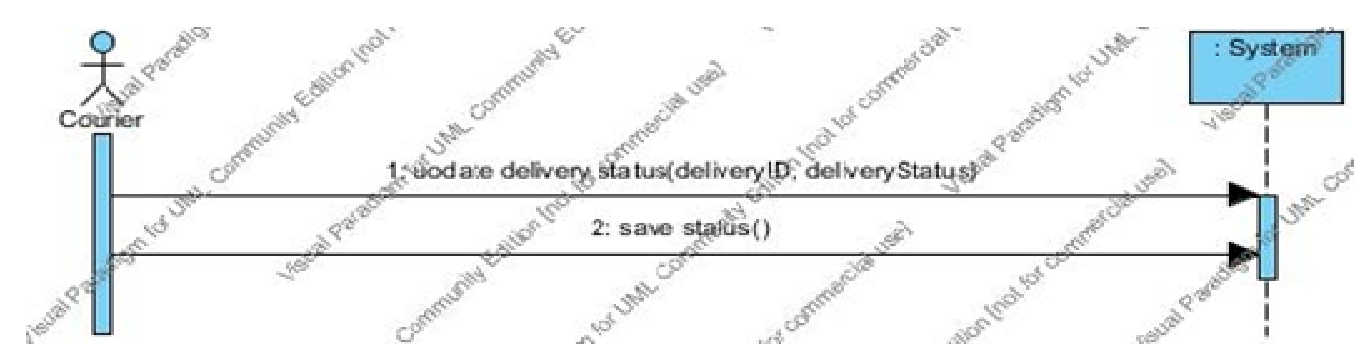

Gambar 7 SSD: Update Delivery Status 


\section{State Machine Diagram}

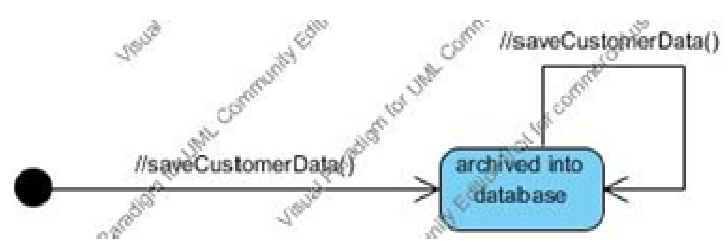

Gambar 8 SMD: Customer

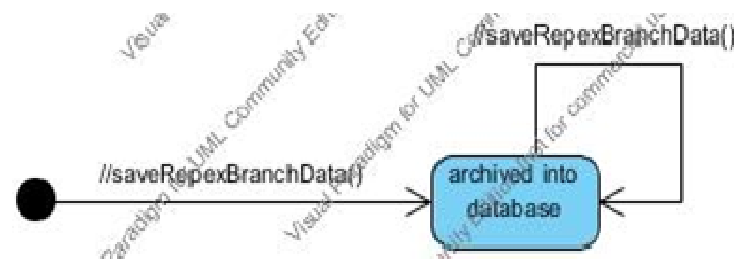

Gambar 10 SMD: Repex Branch

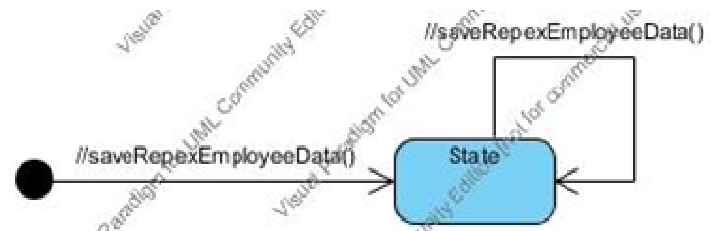

Gambar 9 SMD: Repex Employee

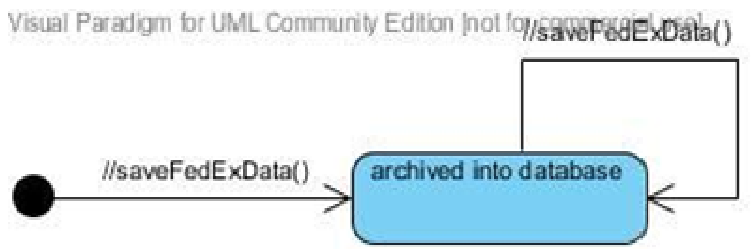

Gambar 10 SMD: Repex Branch

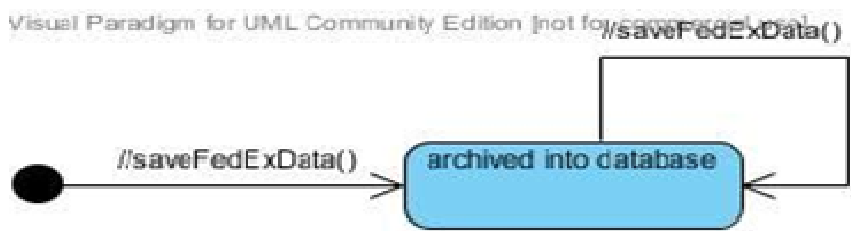

Gambar 11 SMD: FedEx

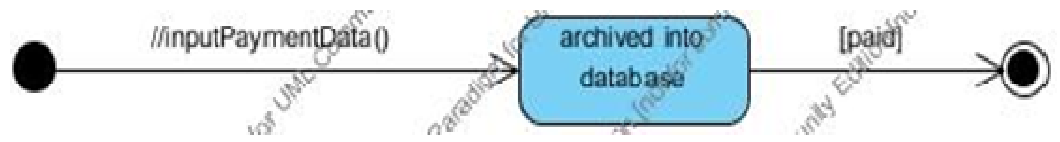

Gambar 12 SMD: Payment

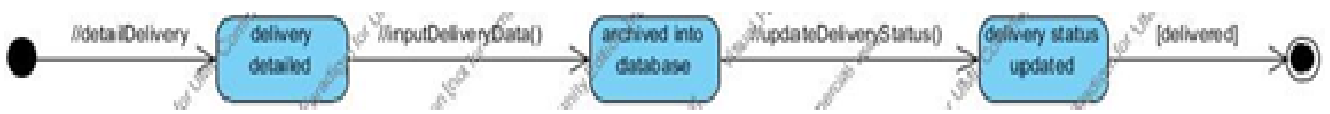

Gambar 13 SMD: Delivery

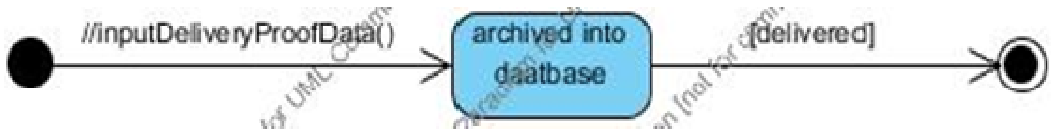

Gambar 14 SMD: Delivery Proof Data 


\section{User Interface}

Delivery Form

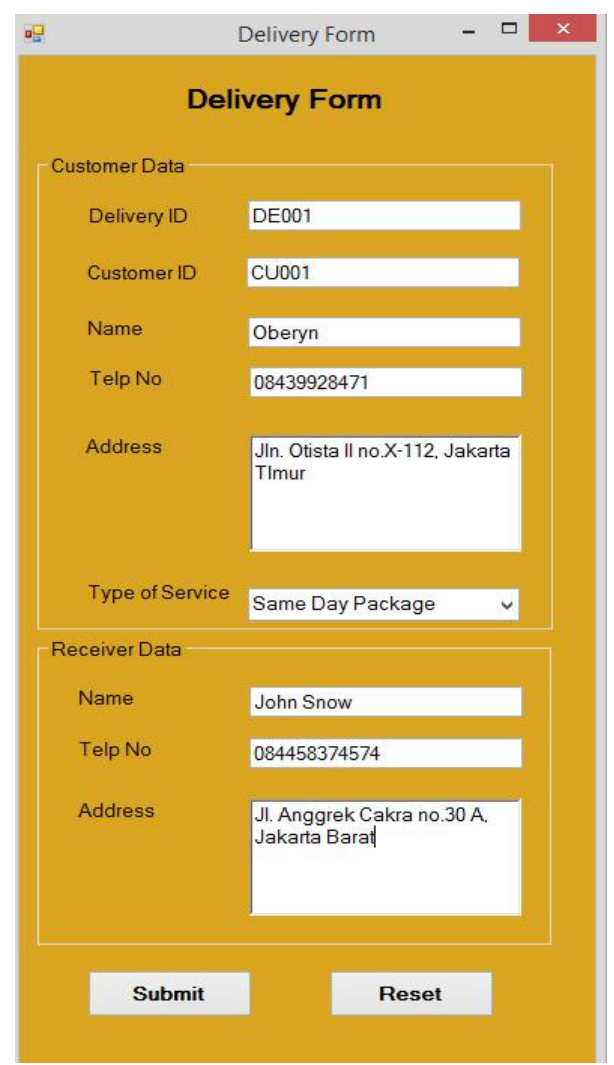

Gambar 15 Delivery Form

Payment Form

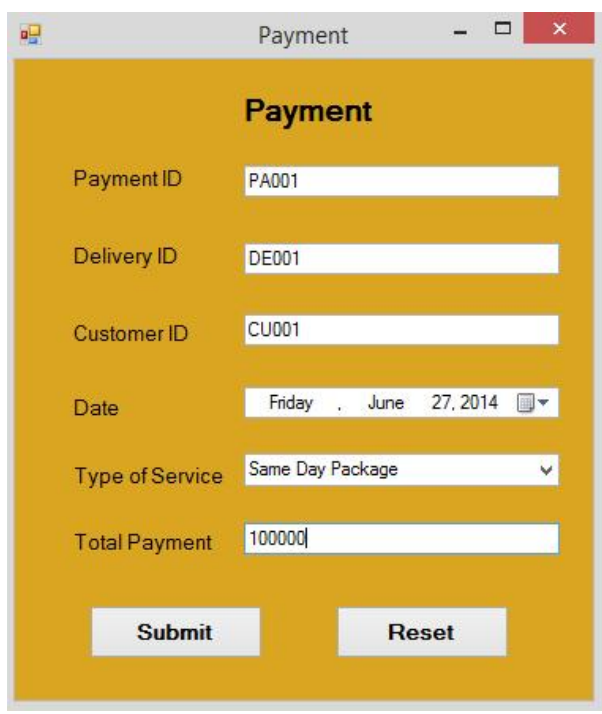

Gambar 17 Payment Form
Delivery Proof Form

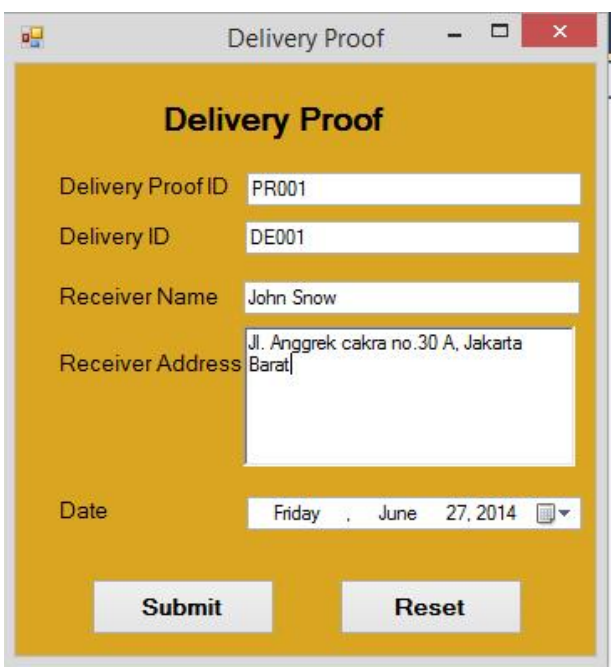

Gambar 16 Delivery Proof Form
Update Status Form

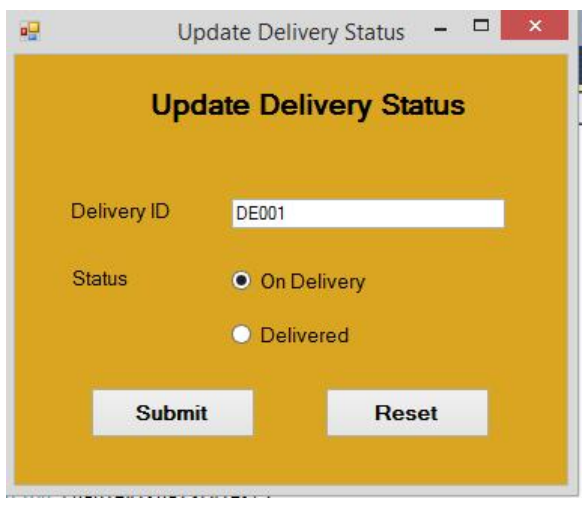

Gambar 18 Update Status Form 


\section{SIMPULAN}

Dari hasil penelitian terhadap PT Repex Wahana, maka diperoleh beberapa fitur yang perlu menjadi requirement utama dalam pembuatan system informasi yang sedang dirancang. Customer tidak dapat mengecek status mengenai barang yang dikirim. Seluruh proses bisnis di RPX masih dilakukan secara manual sehingga sering terjadinya human error yang mengakibatkan penginputan berulang kali untuk data yang sama. Membutuhkan waktu yang cukup lama dalam pencarian informasi yang dibutuhkan untuk membuat dokumen-dokumen yang diperlukan karena dilakukan secara manual dikarenakan pencatatannya yang masih manual.

Perlunya diadakan sesi training dan sosialisasi terhadap seluruh karyawan agar dapat menggunakan sistem baru dalam perusahaan. Pengembangan sistem otomatisasi ini masih perlu dikembangkan sehingga tercipta suatu integrasi dari seluruh proses bisnis sampai dengan proses operasional perusahaan. Masih diperlukan control system, yaitu proses approval dan verifikasi sehingga data yang di-input ke dalam sistem tetap terkontrol dengan baik.

\section{DAFTAR PUSTAKA}

Alianto, H. (2011). Analisis Dan Perancangan Sistem Informasi Penjualan, Persediaan Dan Pembelian Pada Pt Xyz. Journal ComTech, 2(1): 532-538.

Nickels, W. G., McHugh, J. M., McHugh, S. M. (2010) Understanding Business, $9^{\text {th }}$ Edition. New York: MHE.

O’Brien, J. A. (2005). Pengantar Sistem Informasi, Perspektif Bisnis dan Manajerial. Jakarta: Salemba Empat.

Satzinger, J. W., Jackson, R. B., Burd, S. D. (2011) Systems Analysis And Design In A Changing World $6^{\text {th }}$ Edition. USA: Course Technology.

Whitten, J. L., Bentley, L. D., Dittman, K. C. (2007). System Analysis and Design Methods. McGrawHill Publishing.Co 